\title{
Fundamentals of Logic, Reasoning, and Argumentation: An Evidence-Supported Curriculum Targeting Scientific Literacy to Increase Public Understanding and Engagement in Science
}

\author{
La Shun L. Carroll ${ }^{\mathrm{a}}$ \\ ${ }^{a}$ Graduate School of Education, University at Buffalo, Tel.: 401-250-2574, Fax: 401-404-8201 \\ https://orcid.org/0000-0003-4132-6392
}

\author{
ARTICLE HISTORY \\ Compiled December 14, 2018
}

KEYWORDS

Science Technology Society; STS; STEM, Curriculum Planning; Science; design; Education

\section{Abstract}

The American Academy of Arts and Sciences suggested the definition of science literacy emphasize how crucial understanding the scientific process and the ability to evaluate conflicting scientific evidence is. The purpose of this article is to present an evidence-supported curriculum covering the fundamentals of logic, reasoning, and argumentation skills to address the emphasized basic knowledge, skills, and abilities required to be scientifically literate, which will prepare the public to understand and engage with science meaningfully. An analytic-synthetic approach toward understanding the notion of public is taken using a theoretical biomimetics framework that identifies naturally occurring objects or phenomena that descriptively captures the essence of a construct to facilitate creative problemsolving. In the present case, the problem being solved is how to reconcile what is meant by public, how it ought to be interpreted, the different levels of confidence in science that exist, and various understandings of science all with one another. The results demonstrate there is an inherent denotative-connotative inconsistency in the traditional notion of public that can be explicated through the concept of a fractal allowing for comprehension of the relationship between public confidence in, and understanding of, science.

\section{Fundamentals of Logic, Reasoning, and Argumentation for Public Engagement with Science}

In a report by the American Academy of Arts and Sciences entitled "Perceptions of Science in America" [1], it was suggested that additional research needs to be conducted, and it should expand upon the definition of scienceliteracyin a manner that emphasizes the importance of understanding the scientific process and the ability to evaluate conflicting scientific evidence. Conflicting scientific evidence abounds, and there exist a plethora of examples in the media of both faulty reasoning and unfounded claims [2].

Despite all of the deficiencies in the Public Understanding of Science (PUS) on display in the media, the nature of the attitudes of the public toward science tends to be positive [1]. Also, for example, research has demonstrated that although various levels of confidence in science do exist, the majority of people believe that the benefits of science outweigh any potential risks [1]. Moreover, the public thinks the 
highest priority for science should be given to improving educational outcomes, reducing poverty, and finding cures for diseaseand illness [1].

As admirable as the hopes for, and belief in, science may be, it is vital to understand that the publics' trust or confidence is a function of demographics and the particular issue in question [1]. In fact, not only are members of the public found to have different levels of confidence in science but if asked to explain their understanding of the term "science," one would discover that science means something different to each member [1]. That there exists no consensus concerning the public understanding of science as an enterprise should not astonish the reader because the state in which we find ourselves is a logical consequence of the notion of a public that I argue may be responsible for the issues that everyone, including students, has to face.

\subsection{Theoretical Biomimetics as a Framework for Understanding: Fractal Public}

Whether constructing a skyscraper or building an airplane, humankind's most significant source of inspiration has been nature and it will always be its ultimate guide. Similar to the manner in which the principles found in natural things, or those underlying naturally occurring phenomena, are used to drive the development of human-made tangibles such as tall buildings or planes, Carroll [3] has developed an approach to creating intangibles such as solutions in problem-solving, which compares and contrasts principles or phenomena as they exist naturally with realworld problems to gain insight and is referred to as Theoretical Biomimetics (TB). As a tool for analyzing the present issue of understanding what is meant by "public," applying theoretical biomimetics as a framework for recognizing in which way the problem or issue resembles objects or phenomena that are found around us in nature has been incredibly enlightening. Through the TB lens, we discuss what a public is, attempt to reconcile it with public confidence in science, and lastly consider the role that public understanding of science plays.

The dictionary defines "public" as people or community [4]. Additionally, synonyms for the word public according to the same source include "citizens, subjects, the general public, electors, electorate, voters, taxpayers, ratepayers, residents, inhabitants, citizenry, population, populace, society, country, nation, and the world" [4]. If we are to accept the definition of the word public as true on authoritative grounds, then, according to the analysis of the synonyms, interpretation of the definition, and understanding of the word, what makes a public is a group of people who have at least one thing in common. With a clear understanding of the public, we must consider the notion of logical consequence, as it pertains to such a notion as the public. Something that is said to be a logical consequence of another just in case it is impossible for the former to be true without the latter being the case [5]. What concerns us now is how the lack of uniform agreement is a logical consequence of the notion of public.

The primary issue is that it tends to be somewhat misleading when considering the stance on science and related issues while referring collectively to a group of different individuals as members of the same public. Besides, relying on this understanding of public as a starting point to refer to the people as such exposes the conceptually inherent flaw of internal inconsistency or self-contradiction. As a result of the contradiction, anything may be derived or proven, which is to be avoided at all costs. Therefore, to avoid such a logical contradiction, we ought 
to abandon the traditional notion of public and declare that there can be no singular public; there are only multiple publics [1].

Philosophically speaking, the notion of "public" that I hold would be best understood as analogous to "myself watching this video of myself watching this video, ad infinitum." As it so happens, my analogy may be represented more succinctly by the notion of a fractal in which each abstract figure, pattern, or phenomenon comprises progressively smaller versions of itself [4]. That is, to say because public by definition must be comprised of ever smaller publics, I refer to them as a fractal.

If I construct an argument to support the claim that there are many publics, as mentioned and begin with the fact there is a lack of consensus among the public, then it may be more convincing to the reader. For example, borrowing just one potential issue of contention among the public in which there may only be two possible positions for members comprising a public to adopt, either everyone agrees, or they do not. So, unless there was complete unanimity (i.e., 100\% agreement), then the people could be designated according to the position they supported, which would result in two groups. However, if each of the groups consisted of people who share a common position, then, according to the definition provided previously, each group would be considered its own public. In other words, we have discovered that the first public comprises at least two distinct publics. Furthermore, what was true of the first public must be true of each of the two new publics. Of course, continuing along this same line of reasoning would result in each subsequent public containing yet others, and so on.

The takeawaymessage from this thought experiment is that for each property or issue of contention there exist two or more sides; thus, necessarily there is more than one public. Furthermore, if the issue of contention were "what does science mean" or "how does one interpret science," or even "what is your level of confidence in science," then the results would be identical: the existence of a fractal public. Additionally, having multiple publics is consistent with the reality of varying interpretations of science as well as different levels of confidence in science. Given the aforementioned differences in confidence and meaning of science that exist in each public, it may be concluded that the relationship between confidence and public understanding of science is not merely one of association; the relation is one of cause-and-effect. Nonetheless, the cause and effect are not what most would believe. It is not the case that levels of confidence in science cause various meanings of science or how science is interpreted; I contend that the differing levels of confidence in science can be attributed to the different interpretations and meanings that science has to different people.

If there is to be any hope of society moving beyond behavior in the form of flawed reasoning, we must strive for, and engage in, rational discussion. Moreover, if rational discussion requires there to exist a possibility of establishing inferencewarrants, then all parties involved in the engagement must be clear about the sort of problem or issue at hand [6]. Such clarity concerning a particular problem may only be achieved if there can be improvements made in the Public Understanding of Science (PUS). Thus, the process of improving PUS must begin with a concerted effort to remediate the faulty reasoning and unsubstantiated claims that have become the norm.

Despite the legitimacy of science and overwhelming evidence supporting climate change and anthropogenic global warming (AGW), many of the American public remain either skeptical or in complete denial of its truth [7]. The degree of skepticism is much higher in segments of the public on the lower end of SES and 
educational achievement concerning the purported benefits of science and research and the astounding rate at which technological advancement occurs [1]. Nevertheless, given that skepticism id qualitative sm is a qualitative characteristic that is both native and necessary for science [7], in the face of existing evidence, complete denial is not.

That the public can remain in denial suggests a lack of appropriate knowledge, skill, and attitudefor making judgments regarding such issues of scientific concern. Whether skeptical but willing to accept evidence, or skeptical and unwilling to accept any evidence, in order to legitimately claim improvements in the PUS have been accomplished, all members of the public ought to be equipped with basic scientific skills requisite for evaluating issues of concern. Thusly equipped with improvements concerning the PUS, there would genuinely exist a competent public comprised of informed individuals each of who are more likely to participate in fulfilling the role of citizen scientists [8].

Public engagement with science (PES) refers to opportunities for mutual learning and growth that comes about when scientists and members of the public meaningfully and deliberately interact [1]. That notwithstanding, PUS is a prerequisite for PES. Therefore, to remediate the deficiencies in knowledge (i.e., PUS) concerning the basic principles of logic, reasoning, and argumentation necessary for participation in rational discussion (i.e., PES), I have designed a course curriculum addressing them. By availing the public of a seminar entitled "Fundamentals of Logic, Reasoning, and Argumentation for Public Engagement with Science (PES)," individuals who enroll and complete my course will acquire the acumen, ability, and attitude that are essential to contributing to decision-making related to issues of scientific concern. It is through the acquisition of such essential tools that, not only will learners possess what is needed in order to evaluate issues of scientific interest, they will be capable of forming their own opinions and appropriately support their respective stances.

\subsection{Student Factors: Potential Threats to Learning}

Everyone at one time or another has had a learning experience, which consisted of them either mentally or physically doing things that led to changes in their knowledge, skills, or attitudes [9]. Regardless ofthe experience, many factorsthat influenced the outcome of theirlearning efforts. The previouslearning efforts may have been either positive or negative depending on the individual and how they perceived it. No matter how they may have been perceived, such outcomes that comprise the backgrounds and experiences related to learning, culture, family, self-esteem, and confidence, which provide the context within which learners exist. In addition, as a contextual framework within which learners live, background and experience also play a role in constructing or forming what they know, the attitudes they adopt, and any skills that they possess.

For any student learner, naïve conceptions, one's level of maturity, and his or her tendency to challenge authority are all products of their experience that may be categorized under knowledge, skills, and attitudes. Additionally, individuals of greater socioeconomic means may have more learning opportunities and exposures to learning than the less fortunate, which affords them chances to improve their attitude, correct knowledge deficiencies, or perfect a skill. Nonetheless, regardless of student SES and despite the many potential factors that have the potential to detrimentally impact the 
learning outcomes, there is one key aspect of related to my course offering that I claim effectively neutralize most if not all the other potential student factors: the elective nature of course enrollment.

In an academic setting, professional enrichment program, or other formal environments in which registration for specific courses may be compulsory, among enrolled students there will exist factors that profoundly influence whether learning outcomes can be achieved. Nonetheless, the elective nature of enrollment in my course ensures that the students who ultimately enroll will be mature, motivated, interested, and confident. Moreover, the remaining factors such as socioeconomic status (SES) are also neutralized efficiently through the elimination of attendance costs thanks to both public and private funding obtained. In addition, those attendees with little-to-no-science background coursework or who have previously performed poorly will likely possess inadequate basic science skills, which would understandably be expected to place them at a disadvantage in other courses. However, the need to acquire these skills will not impair their ability to succeed in my class because it was designed according to principles of a learner-centered curriculum [9], which is selfcontained so as to facilitate the process of learning to allow every student to accomplish the primary course goal by providing what they will need without relying on prior experiences.

\subsection{Factors Forms}

Intentional and Unintentional Factors. Indeed, there can be no way to know with absolute certainty who shall attend my course. Nevertheless, I anticipate that, along with these students, there will exist various challenges that come with them as a result of both intentional factors and unintentional ones. Although many recognized challenges do exist, I feel it is necessary to distinguish between at least two varieties of a factor that will present as challenges due to their potential to affect students' ability to achieve an educational goal: Intentional and Unintentional Factors.

\subsubsection{Unintentional and Intentional Factors}

Unintentional factors I claim would be those circumstances, outcomes, or experiences over which students exert little to no control. An example of an unintentional factor would be having been raised in poverty or a low SES as a child, or suffering from a developmental disability. As opposed to unintentional ones as we have already mentioned, an intentional factor would be something over which one does have legitimate control, yet he or she fails to exert it for whatever reason. It is crucial to understand that, in such cases, a factor at play need not result from the commission of an act in order to qualify as being intentional.

\subsubsection{The Case of Obstinacy as a Factor Form}

For instance, were a student to exhibit obstinacy related to a naïve conception held just discovered by him in class to be impossible, the student's refusal to cooperate by responding with the appropriate response (i.e., inaction) would be considered intentional. Now, unlike unintentional factors, such deliberate stubbornness by a student in class allows me to infer that a reason -or more accurately, an absence of reason- for such behavior exists. I would argue that the absence of reason would be related to a lack of motivation, interest, or incentive. In other words, if the student 
had the motivation to acknowledge the naïve conception was incorrect, interest in it being incorrect or determining what is correct, or incentive to come up with the correct response, then the intentional factor of stubbornness would cease to exist.

As a science educator, knowing that I would be unable to repair or replace any of the horrible experiences some students endured that may serve as unintentional factors (e.g., poverty) impeding both the efforts of students and myself would be disheartening. However, in the case of my course, since any student will either have intentional, unintentional, or both factors to contend with while learning in my course, fortunately, by virtue of there being no enrollment costs, registration being entirely voluntary, and made available on a first-come-first-served basis, not only will the majority of unintentional factors be directly and effectively neutralized (e.g., SES), but given the voluntary signup, each enrollee had to be already motivated, interested, and have the incentive to do so. In this fashion, my course offering also attempts to indirectly ensure that the potential for any remaining factors to be present - intentional or otherwise- is significantly reduced before the course even begins. While not guaranteed to eliminate all the potential challenges in the form of factors, efforts were put into all aspects of the course that are guaranteed to eliminate some factors. Upon their elimination, these student factors no longer threaten to detrimentally impact the material being taught or learned in the class.

\subsection{Learning Goals}

Learning goals may be understood as what students should be able to accomplish upon completing a course of study [9]. The visible result of completing my course would be that attendees will be capable of making their own independent assessment concerning scientific issues in society using logical reasoning and argumentation.

A Thorough understanding of science basics and an ability to employ logic, reasoning, and argumentation routinely to facilitate learning. Ultimately, successful students will find that education becomes a process of self -propagation. For instance, individuals claiming to know A, B, and C, for example, should be able to employ the skills that they have learned and, relying on them as premises, derive D; then, with $\mathrm{A}, \mathrm{B}, \mathrm{C}$ and $\mathrm{D}$, conclude that $\mathrm{E}$ is the case. Possessing the ability to determine for themselves what justification -if any- there may be for believing something, whether that something is, in fact, real, and claiming to know that something is hugely empowering. Moreover, from this starting point, they may metacognitively engage themselves deducing from what is already known to add to their knowledge base as well as assess whether new claims are consistent with what is already known and why

General learning goals (GLGs) for the course include the following: 1) ability to make logical decisions relying on available evidence concerning scientific issues; 2) be capable of forming their own opinions regarding public policy and contribute to dialogue on critical issues in public discourse; 3) employ the acquired knowledge and skill to determine the best course of action with regard to their behavior and of those for whom they are responsible including both relatives and the public. 


\subsection{Goal Descriptions}

GLG 1 entails the use of logic, reasoning, and argumentation, to increase knowledge and to aid in decision-making according to a rational process that relies on available sources of evidence concerning particular scientific issues. GLGs 2 and 3 may be understood as giving students the tools needed to allow them to construct their own opinions regarding private (i.e., personal ethics) and public policy, thereby to equipping them with the ability to contribute to dialogue and discourse in the public forum. Of the GLGs, it is GLG 1 that serves as the primary learning goal for participants and is what guided curriculum design.

\subsection{Summative Assessment}

A summative assessment is used to evaluate the level of student comprehension and is given at the end of a course. Like the formative assessment, the summative assessment was aligned with the goal of the course. Aligning the summative assessment in such a fashion is akin to a method of validating that the course content, experiences, formative assessment, and proficiencies measure or reflect that students learned what they were supposed to learn. The summative assessment for my course is the following project:

Given the available evidence regarding the phenomenon of global warming and climate change, conduct a review of the literature and choose 5 research papers claiming to support and 5 claiming to refute its occurrence. Then, analyze the evidence presented and using logic and reasoning, determine your stance on the issue and present an argument in support of it.

\subsection{Learning Proficiencies}

In order to achieve the goals of this course, attendees must possess specific knowledge, skills, and attitudes (KSAs). Without these KSAs, students will be unable to move closer toward the ultimate learning goals of the course. Each step of the way students will acquire these KSAs to the point of proficiency so as to progress; Thus, since progression hinges on students' becoming proficient through "the acquisition of KSAs," the KSAs are referred to as Learning Proficiencies. Table 1 comprises the learning proficiencies (i.e., KSAs) for this course. The proficiencies in Table 1 have been categorized according to the Type by row and column, which allows for a coordinate designation to describe each one. For instance, the ability to recognize the basic structure of an argument comprising scientific evidence is located in row 2, column 2. The basis for the coordinate location system I decided upon is that an ability to recognize an argument requires knowledge of its general structure. Furthermore, though this proficiency may rely on knowledge that is derived from the cohesiveness of facts that yield concepts, it is neither factual nor itself a concept; I propose that the proficiency may be conceived of as an ability that results from a thorough understanding of the concepts derived from the knowledge of isolated facts.

Although it does a great job organizationally, Table 1 is descriptive. The descriptive elements in the table may be improved upon, in my opinion, by the adoption of an alternate framework. Instead of rightfully viewing learning proficiencies as merely being descriptive of the outcomes of a metaphoric "course goal equation," I wondered whether altering perspectives on either the goal, the equation itself, or both would lead to greater insights. Ultimately, it would be changing my perspective on the equation 
that made the most sense. By viewing each of the learning proficiencies as components of the overall goal equation that are individually necessary yet only sufficient together they have been transformed into what students ought to know, what they should be able to perform, and the attitude they should have to allow them to realize the outcomes of the course.

Table 1.: Descriptive Learning Proficiencies for Fundamentals of Logic, Reasoning, \& Argumentation

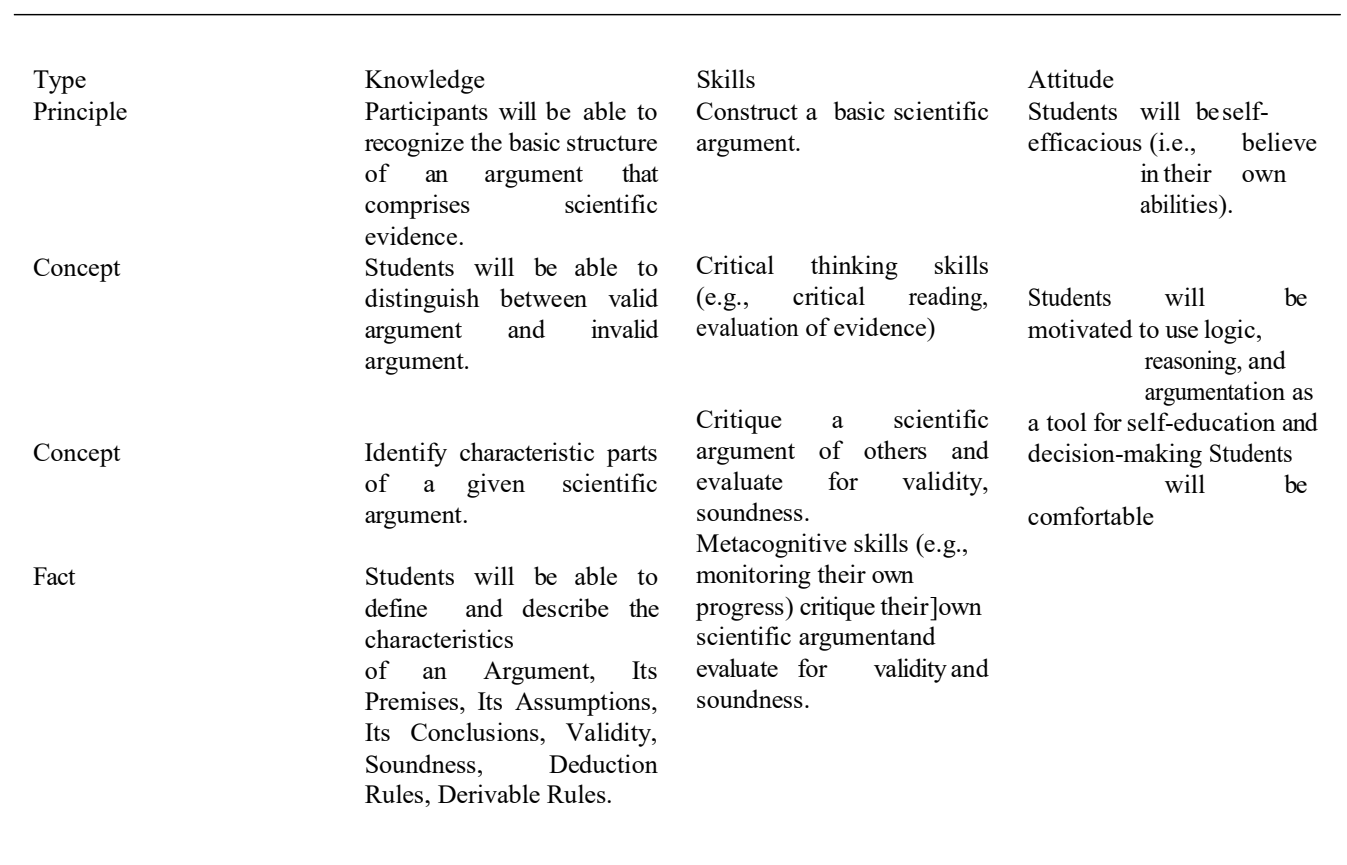

Table 1. Proficiencies have been cross-tabulated by type only resulting from viewing them as descriptive.

\subsection{The Curriculum Title and Its Target Audience}

Fundamentals of Logic, Reasoning, and Argumentation for Public Engagement with Science (PES). The target audience includes adult students who are members of the public not considered scientists by profession.

Course Sequence and Description Of The Rationale For The Curriculum (Why It Is Needed, Your Approach To Educating Students Or The Public)

The curriculum is necessary for multiple reasons that relate to understanding and engagement with science. For instance, interest in science is growing while scientific literacy is decreasing [10]. Scientific literacy is required to understand as well as engage with science in any meaningful capacity. Moreover, with neither understanding nor engagement by the public (comprising yet other publics, which are themselves made up of still more publics), policies cannot be shaped by citizens it is meant to benefit. Furthermore, public policy concerning scientific issues can neither be said to truly benefit those who fail to understand nor participate in its establishment.

The Overall Goals And Specific Objectives You Expect Your Audience To Achieve After Completing The Curriculum 
Table 2. Descriptive Learning Proficiencies for Fundamentals of Logic, Reasoning, \& Argumentation

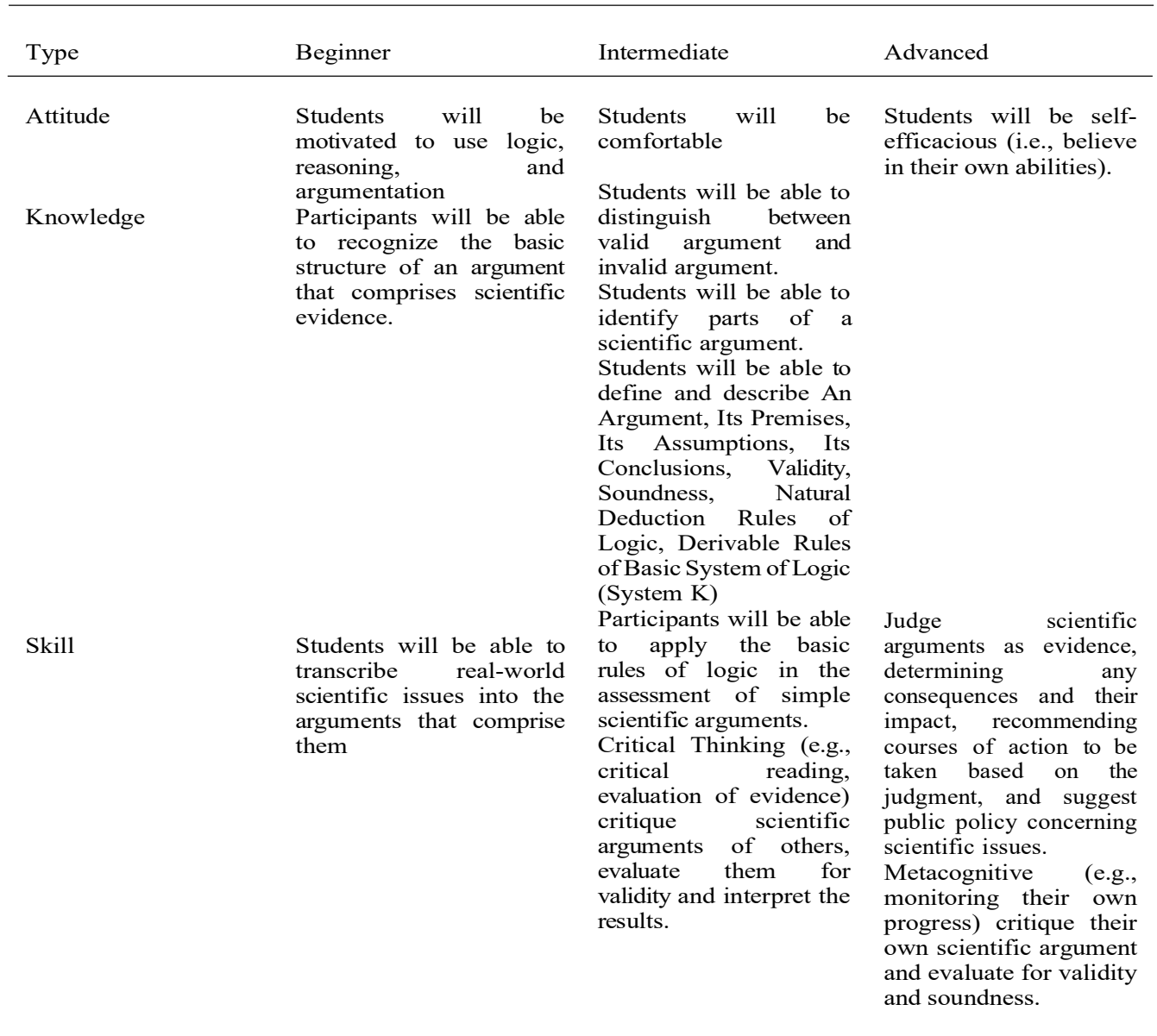

\subsection{The Overall Goals And Specific Objectives You Expect Your Audience To Achieve After Completing The Curriculum}

(1) Participants will be able to recognize the basic structure of an argument that comprises scientific evidence (need to know parts, simple logic).

(2) Students will be able to define and describe the characteristics of An Argument, Its Premises, Its Assumptions, Its Conclusions, Validity, Soundness, Natural Deduction Rules of Logic, Derivable Rules of Logic (System K).

(3) Students will be comfortable in judging scientific arguments as evidence, determining any consequences and their impact, recommending courses of action to be taken based on the judgment, and suggest public policy concerning scientific issues. 
Table 3. Angelo \& Cross' (1993) Classroom Assessment Techniques (CATs) That Will Be Among Those Implemented in the Assessment of Course-Related Knowledge, Skills, and Attitude.

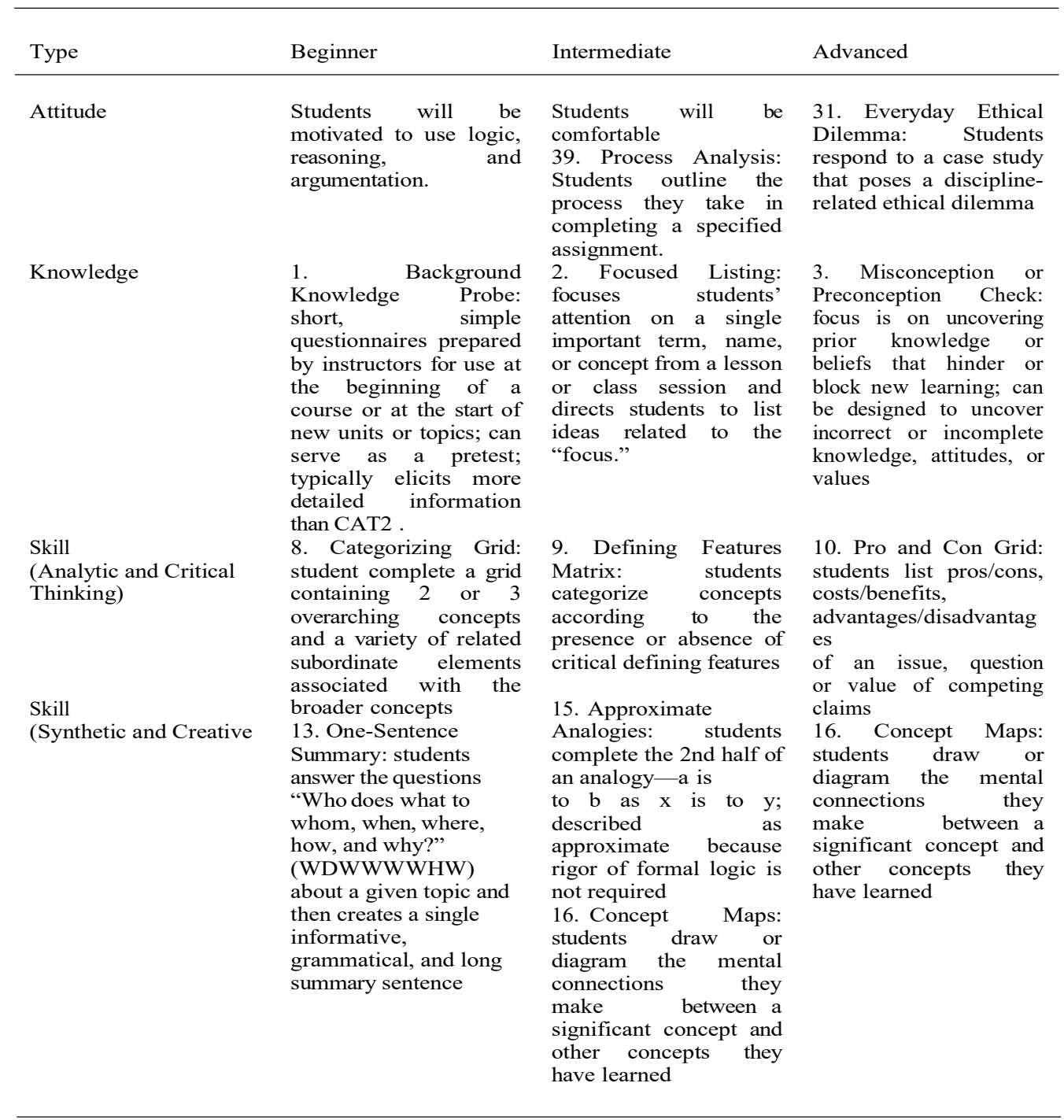

Table 3. As found in the text by Angelo, T. A., \& Cross, K. P. (1993). Classroom assessment techniques: A handbook for college teachers [Kindle 6].

\section{Materials And Resources Needed To Implement The Curriculum}

James Garson; Modal Logic (2016)

Barker-Plummer, D., Barwise, J., Etchemendy, J., Liu, A., Murray, M., \& Pease, E. (2011). Language, proof, and logic (Vol. 2). CSLI Publications Stanford, CA. Retrieved from https://ggweb.gradegrinder.net/assets/1.o-SNAPSHOT/ctx/Openproof/DBP-L PL-OpenproofDay.pdf 
Toulmin, S. E. (2003). The uses of argument.

A Description Of Evaluation Activities To Be Conducted To Find Out If The Curriculum Goal And Objectives Are Met.

Angelo, T. A., \& Cross, K. P. (1993). Classroom assessment techniques: A handbook for college teachers [Kindle 6].

\section{References}

[1] American Academy of Arts and Sciences (AAAS). America; 2018.

[2] Diethelm P, McKee M. Denialism: what is it and how should scientists respond? European Journal of Public. 2009;19(1):2-4. Available from: https://doi.org/10.1093/eurpub/ ckn139.

[3] Carroll LSL. Theoretical Biomimetics: A biological design-driven concept for creative applied to the optimal sequencing of active learn ing techniques in educational theory. Multidisciplinary Journal for Education, Social and Technological Sciences. Multidisciplinary Journal for Education, Social and Technological Sciences. 2017;4(2):80-96. ISSN 2341-2593. Available at:

<https://polipapers.upv.es/index.php/MUSE/article/view/7078>. Date accessed: 14; Available from: 10.4995/muse.2017.7078; https://doi.org/10.4995/muse.2017.7078.

[4] Stevenson A, Waite M. Concise Oxford English Dictionary: Luxury Edition. OUP Oxford; 2011. Available from: https://market.android.com/details.

[5] Barker-Plummer D, Barwise J, Etchemendy J, et al. Language, proof, and logic (Vol. 2). Stanford, CA: CSLI Publications; 2011.

[6] Toulmin SE. The uses of argument. 2003.

[7] Dunlap RE. Climate Change Skepticism and Denial: An Introduction. The American Behavioral Scientist. 2013;57(6):691-98. Available from: https://doi.org/10.1177/ 0002764213477097.

[8] Mejlgaard N, Stares S. Participation and competence as joint components in a cross-national analysisof scientific citizenship. Public Understanding of Science.2009;19(5):545-561. Available from: doi:10.1177/0963662509335456; Mejlgaard,N.,\&Stares,S.(2009).Participationandcompetenceasjointcomponentsinacrossnati onalanalysisofscientificcitizenship.PublicUnderstandingofScience,19(5),545-561.doi: 10.1177/0963662509335456.

[9] Jones SK, Noyd RK, Sagendorf KS. (2015).Building a Pathway to Student Learning: A How-To Guide to Course Design. ? Available from: https://market.android.com/ details.

[10] Suleski J, Ibaraki M. Scientists are talking, but mostly to each other: a quantitative analysis of research represented in mass media. Public Understanding of Science. 2010; 1(115-125). Available from: https://doi.org/10.1177/0963662508096776.

\section{Author biography}

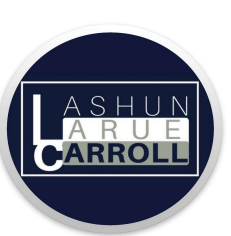

La Shun L. Carroll is an Ed.M. graduate student at the University at Buffalo Graduate School of Education. He received his Doctorate Cum Laude from the University at Buffalo School of Dental Medicine, and a B.A. Magna Cum Laude in Philosophy from Baruch College. His publications include "Theoretical Biomimetics: A biological designdriven concept for creative problem-solving as applied to the optimal sequencing of active learning techniques in educational theory" in Multidisciplinary Journal for Education, Social and Technological Sciences (October 2017), and "A Comprehensive Definition of Technology from an Ethological Perspective” (MDPI, 2017). Research interests include metaphysics, logic, science, technology, and education. Dr. Carroll was an Adjunct Professor at Saint Michael's College. 